\title{
Kerk en kultuur by die vryheidsoekende Afrikaner van die 19e eeu - 'n historiese ondersoek
}

A D Pont

Emeritus-professor: Departement Ke. kgeskiedenis en Kerkreg (Afd A)

Universiteit van Pretoria

\begin{abstract}
Church vis à vis culture among the republican Afrikaner of the 19th century - an historical investigation

In this study attention is given to the question of the correlation between and/or position of the church vis à vis culture among the republican Afrikaner of the 19th century. Initially attention is given to a workable definition of church and culture and then, in the light of Calvinist theology, the relationship is discussed. Eventually the stated problem is discussed and the conclusion formulated that the culture of the Afrikaner was strongly influenced and directed by its theological viewpoints. A few conclusions are drawn.
\end{abstract}

\section{INLEIDING}

Die vraag na die verhouding tussen kerk en kultuur was in die Nederlandsprekende kerklike wêreld aan die begin van ons eeu 'n saak wat nogal aandag getrek het (Van Ruler s a:6). Veel breër is dié saak egter nie hanteer nie. In 1991 is dié saak egter weer aan die orde gestel by die vergadering van die Wêreldraad van Kerke wat in Canberra gehou is. Daar is gestel dat kultuur 'n struikelblok is om éen, oorkoepelende en omvattende kerk te bou waarin mense van verskillende herkoms en kultuurtradisies tuis kan wees (Kinnamon 1991:xiii, 241). Dáár word veral gewys op die spanning tussen die kerk as geloofsgemeenskap en die kultuur van mense wat in 'n nie-Christelike leefwêreld bestaan. Dit word ó́k duidelik dat die problematiek in verband met die verhouding tussen kerk en kultuur op 'n ander vlak lê in tradisionele Christelike gemeenskappe en volke as by volkere én mense waar die gehoorsaamheid aan die lewende God nog nie 'n duidelike gestalte in hulle leefwêreld verwerf het nie (vgl o a Van Niekerk 1992:48vv). In die kringe van die Wêreldraad vir Kerke waar die eenheid van die kerk soms belangriker geag word as 'n Bybelse teologie (vgl Labuschagne 1987:22-74), lê die antwoord op hierdie vraag in die opneem van die volkskultuur in die kerk en selfs die ombuig van die evangelie om die kultuur te akkommodeer. Die voorwaarde vir 
hierdie verhouding tot die kultuur is dat so ' $n$ verhouding nie mag bestaan met ' $n$ reeds gekerstende kultuur nie. Dan moet daar 'n duidelike afstand tussen kerk en kultuur, geloofsgemeenskap en menslike.leefwêreld wees.

Hierdie situasie, veral in die WRK-denke, word gekompliseerd wanneer die gedagte van multikulturaliteit in die kerk gepropageer word om die 'standaardoplossing' van die Westerse liberalisme of die wetenskaplike sosialisme op die vraag na die saambestaan van verskillende volkere en kulture in een land, aanvaarbaar te maak. Volgens dié social engineering-teorie is die bindingskrag van die evangelie en die geloofsgemeenskap sterker as die gelowige se natuurlike kultuurerfenis en kan dit nie 'n struikelblok wees nie. Die nogal merkwaardige ontstaan en voortbestaan van groot getalle sektes onder die swart bevolking van Suid-Afrika, is ' $n$ interessante verskynsel naas die poging om multikulturele geloofsgemeenskappe met die Bybelse boodskap as die sentrale bindende element, te bou. Merkwaardig veral omdat afkoms, tradisie, taal en kultuur blyk om sterker saambindende faktore te wees as godsdiens alleen (vgl Taylor 1992:357). Die vraag ontstaan dan of die begrip multikulturaliteit nie 'n teenspraak in homself is nie. In Suid-Afrika, as gelet word op die openingsfunksie van die nuwe $\mathrm{SABC}$, beteken multikulturalisme nie veel meer as 'n Engelstalige Amerikaanse Negerkultuur nie.

In die lig van die omstandighede is dit seker gewens dat 'n oomblik gekyk sal word na die $19 \mathrm{e}$ eeuse Afrikaners en hulle verstaan en uitlewing van die twee werklikhede, kerk en kultuur. Dit is dus voor die era van social engineering wat so 'n vanselfsprekende onderdeel van die ideologies-bepaalde samelewings van die $20 \mathrm{e}$ eeu geword het. In die $19 \mathrm{e}$ eeu was die langs-mekaar-bestaan van kulture én volke baie meer vanselfsprekend as die 20e eeuse ideaal om onder die rookskerm van multikulturaliteit 'n ideologies-bepaalde monokultuur te vestig. Daarom kan hierdie studie miskien net 'n sydelingse waarde hê as multikulturaliteit 'n doelwit is.

\section{KERK EN KULTUUR: 'N POGING OM DIE VRAAGSTUK TE OMLYN}

Wanneer die vraag na die verhouding kerk-kultuur gevra word, is dit seker nodig om die inhoud van die twee begrippe kerk en kultuur te omlyn. Veral ten opsigte van die begrip kerk bestaan daar soveel omskrywings dat dit nodig is om uit te wys wat daarmee bedoel word. Dié probleem word nogal bemoeilik vanweë die feit dat in die 19e eeu die genootskapkerkbegrip ontstaan wat byna allerweë in die openbare lewe as die beste beskrywing van die begrip kerk beskou word. So algemeen word dan die opvatting dat die kerk maar soos enige ander vrywillige vereniging of genootskap is wat bepaalde doelwitte nastrewe, dat dit die opvatting van die owerhede en die burgerlike reg oor die kerk bepaal. Dit op sy beurt, hang weer saam met die min of meer WesEuropese opvatting van 'n demokrasie en die struktuur van so 'n staatsgemeenskap. 
Die kerk self het homself egter, in die Calvinistiese tradisie, beskryf as 'n geloofsgemeenskap wat rondom Woord en sakrament versamel is (vgl NGB, art 27-32 en HK S 21). So gesien is die kerk 'n gemeenskap van gelowige gesinne en mense wat leef uit die vertikale verbondenheid met die enigste Hoof van die kerk, die Here Jesus Christus. Dié siening bly in die kerk leef nieteenstaande die geslote wêreldbeeld wat so algemeen in die hedendaagse kultuur aanvaar word. Uit die aard van die saak is daar heelwat druk vanuit die burgerlike wêreld rondom die kerk om die kerk te omskrywe as dieselfde as enige ander vrywillige vereniging van mense. Tog word die self-omskrywing van die kerk as 'n geloofsgemeenskap-van-mense met 'n vertikale verbondenheid aan die Drie-enige God, deur die kerk self gehandhaaf (vgl die Kerkwet van die Nederduitsch Hervormde Kerk, Art 1).

Omdat die kerk as geloofsgemeenskap-van-mense in die wêreld bestaan, is dit uit die aard van die saak ó́k 'n kultuurverskynsel. Daarmee word die ingewikkeldheid van die vraag na die verhouding tussen die kerk en die kultuur beklemtoon. Die vraag ontstaan soms, wanneer dié probleem bespreek word, of die omskrywing van die kerk nie beperk word sodat dit slegs die beroepsteoloë aandui en nie die kerk as 'n omvattende geloofsgemeenskap nie.

Wanneer na die begrip kultuur gekyk word, word dit duidelik dat die wortels van hierdie begrip in die Latynse woord colere lê. Dan word dit allereers verstaan as die mens se bewerking, benutting en besig wees met alles wat in die skepping gegee is. Dan dui die begrip kultuur ook op sake soos beskawing, ontwikkeling en verfyning, sodat gesê kan word dat alle aspekte van die menslike handel en denke kultuur is. As dit gesê word, is dit ook duidelik dat kultuur nie 'n saak van 'n-mens-alléén is nie want kultuur het altyd 'n sterk, byna bepalende, gemeenskaplikheid. Dit word veral duidelik as die nasionale aspek, die volksmatige, in die kultuur erken word.

Om die begrip kultuur in ' $n$ enkelvoudige omskrywing raak te vat is nie so eenvoudig nie, juis omdat die vermoë van die mens so wyd loop. Kultuur is nie net innerlik, iets van die gees nie, maar ook uiterlik sigbaar. Dit blyk al daaruit as die materiële onderbou van alle kultuur in ag geneem word. Uiterlike kultuuruitings, soos kuns of wetenskap, is nie net sigbaar nie maar terselfdertyd is die uitbou daarvan alleen moontlik as die ekonomie di: moontlik maak. So gesien, kan dan gesê word dat kultuur die geheel van waardes, gedrag en simbole is en veral die nianier waarop 'n gemeenskap en 'n volk daarvolgens sy plek in die wêreld en die betekenis en inhoud van sy lewe daarvolgens verstaan en rig (Kinnamon 1991:102).

Kultuur as omskrywing van alles wat die mens doen, wortel uit die aard van die saak in die sonde en daarom is daar geen vanselfsprekende kontinuiteit tussen die evangelie en die kultuur nie. Die antitese betrek ook die kerk in sover die kerk 'n gemeenskap van gelowiges is. Die kerk as ' $n$ geloofsgemeenskap groei nie uit ' $n$ natuurlike wortel nie en daarom is kerk en buite-kerklike kultuur nooit dieselfde nie. Dit 
word veral duidelik in dié sin dat die evangelie van Jesus Christus nooit in die wêreld pas nie, want die mens en alles wat van die mens is, ook die kultuur, staan onder die deurtastende kritiek van die ewigheid op die tyd. Die kultuur as beskrywing van die menslike is nie van die ewige nie, dit is van hierdie, tydelike lewe. Van die kant van die kultuur is daar vanselfsprekende verset téén die evangelie wat die einde van die kultuur en die geskapenheid aankondig. Die beskrywing van die antitese tussen kerk en kultuur is waar en geldig in 'n betreklik enkelvoudige situasie wanneer die kerk in 'n wesenlik-heidense wêreld inberweeg, soos in die tyd van die vroeë kerk. Maar dit hoef nie altyd so te wees nie.

Dit is tog so dat die evangelie, die vreemde Woord van God wat van buite af na die mens toe kom, ook die mens wat 'n kultuurskepper en 'n kultuurdraer is, aanraak en teen homself in, die mens omvorm en nuut maak. Die nuwe mens, dic gelowige, die gelowige gemeenskap, leef nog steeds in die wêreld, bly selfs as 'n gelowige 'n sondaar en kom in hierdie wêreld nie juis verder as dat hy maar "' $n$ nietige begrip van hierdie gehoorsaamheid' (HK S44) aan God het nie. Die kritiese vraag word nou of die gelowige met sy hele lewe, in die totaliteit van sy menswees, vanuit die geloof, vanuit die gehoorsaamneid aan God lewe. As en in sover dit gebeur, stempel sy geloof ook sy kultuur, sy manier van lewe en is daar nie noodwendig ' $n$ antitese tussen die kerk, wat as draer van die evangelie in die wêreld ook 'n kultuurverskynsel is, en die gekerstende kultuur van die gelowige volk in wie se midde die kerk leef nie. So is, byvoorbeeld, kerksang en kerkmusiek ó́k uitings van die kultuur van die mens. Dan is dit geheiligde kultuur en word dit uitdrukking van die gehoorsaamheid aan God. So gesien is die antitese tussen die onvolmaakte, betreklik-heilige kerk en die kultuur van die betreklik-gelowige volk, grotendeels ' $n$ fiksie. Net so is die poging om 'n antitese te poneer tussen die kerk en politiek óók betreklik indien, soos by Calvyn, die regsorde van die samelewing op die Nuwe Testament (1 Tim 2:1-4) gebou word (vgl Inst iv 20, 3).

Die vraag na die verhouding kerk en kultuur kan nooit 'n enkelvoudige vraag wees nie omdat nóg die begrip kerk nog die begrip kultuur eenduidig is of kan wees. Daarom kan 'n eklektiese gebruik van dié begrippe om dan 'n prinsipiële verskil aan te dui, nie wetenskaplik verantwoord word nie. Die vraag bestaan of die populêre 'teenstelling' tussen kerk en kultuur wat in ons kerk vanaf die twintigerjare van hierdie eeu gangbaar was, nie juis 'n misleidende en daarom 'n vals teenstelling was nie. Dit het, onder andere, beteken dat die probleme vir die kerk as geloofsgemeenskap, wat deur die owerhede en politieke partye geskep is, nooit op die kansels behandel is nie.

Die teenstelling tussen kerk en kultuur, asof dit twee teenoor mekaar staande afgeronde groothede is, herinner aan die situasie in die Rooms-Katolieke Kerk toe die 
monnike-vroomheid en ideaal daar die botoon gevoer het. Dié ideaal, met sy sterk etiese inslag, wou deur die wegvlug uit 'die wêreld', die ware regverdigheid en heiligheid nastreef en gryp. In 'n sekere sin was dit ook 'n strewe na 'sondeloosheid'. Die probleem met die monnike-vroomheid is egter dat die enigste geregtigheid wat sinvol is, die toegerekende geregtigheid uit genade is. Dit kan die mens slegs van God ontvang. Die grond vir die werklike geregtigheid is die regverdiging deur die geloof alleen. Dié regverdiging skep die geregtigheid en impliseer die heiligheid. In hierdie geregtigheid word die lewende God, volgens sy Woord gedien.

Die problematiek rondom die monnike-vroomheid en die menslike strewe na geregtigheid is in die 16e eeu deur die Reformasie hanteer. In die 19e eeu, met sy sterk antroposentriese uitgangspunte, is dieselfde stryd, net met ander woorde, weer oorgestry. Toe het dit gegaan oor die afwys van die sogenaamde 'dogmatiese godsdiens' en die beklemtoning van die etiek. Met die verskuilde Pelagiaanse standpunt in die oorbeklemtoning van die etiese, was daar ' $n$ wegbeweeg van die Bybelse leer dat die lewe van die mens vanuit die geloof in Jesus Christus, die gekruisigde en opgestane Here, wat 'n genadegawe van die uitverkiesende God is, gedra moet word. Dit blyk daaruit dat die hele saak van die herskepping in en deur Christus nooit verreken is nie. Die sondaarmens wat deur die geloof in Christus bevry word uit die slawerny van die sonde, word daardeur 'n slaaf van Christus en herstel in die lewensorde wat God eis (Rom 7:4-6). Hoewel nie absoluut nie, leef die gelowige in die totaliteit van sy eksistensie nou vanuit die dankbaarheid-in-die-verlossing (Rom 7:17-25; Rom.8), en dít stempel, uit die aard van die saak, die lewenswyse, die kultuur van die gelowige.

Dit is die groot wins van die Reformasie teenoor die Rooms-Katolieke asketisme, dat die Reformasie die natuurlike lewe weer kon waardeer. Dit vanweë die hernieude besinning oor die waarheid van die versoening deur Christus en die regverdiging in Hom (Van Ruler 1938:200vv). Dit beteken dat die natuurlike lewe en die werklikheid in Christus gered is. Dit is juis van wesenlike belang om die verhouding geloof en werklikheid, Christendom en kultuur, kerk en staat, genade en natuur reg te verstaan, want dit maak sowel die sintese as die diastase van dié begrippe onnodig en ongewens.

So gesien is die kontra-stelling kerk: kultuur aanduiding daarvan dat dit wat hiér ter. sake is, nie behoorlik deurdink is nie. Net so is die oorbeklemtoning van die etiese, asof die geloof daarin moet opgaan, net soos die monnike-vroomheid wat teenaan die heidendom lê omdat dit weier om te aanvaar dat die mens self die sonde is (Rom 7:14). Hier is Calvyn se dialektiese siening van die sondaarmens in die wêreld baie nader aan die waarheid as die hedendaagse teologiese vlug na die etiek toe.

Calvyn herhaal die Bybelse eis wat stel dat die doel van die gelowige se lewe die verheerliking van God is én die vergader en heilig hou van die gemeente in die wêreld. 
Wanneer die lig van die Woord oor die hele lewe van die mens val, dan word die groot lyne van die lewensorde wat God van die gelowige vra, duidelik. Dán begryp die gelowige dat hy op elke lewensterrein, ó́k op die maatskaplike, ekonomiese en staatkundige terrein, volgens die wil van God moet leef en handel. Dus vanuit die regverdiging deur die geloof alléén beweeg die gelowige na die gehoorsaamheid-heiliging in die wêreld, terwyl hy weet dat Christus nie net Hoof van die kerk nie, maar ook Heer van die wêreld is.

Die vlug na die etiese en die verwerping van die 'dogmatiese godsdiens' het die gevolg gehad dat in die kerk die yslikheid van die sondeval nie besef word nie. Die gemeenskap van die gelowiges gaan nog 'n duur prys betaal omdat die Reformatoriese teologie ingeruil is vir die oppervlakkigheid van die postmoderne denke. In ieder geval is dit so dat die vraag na die lewe van die gelowige in die wêreld nie omvattend beskryf kan word vanuit die vertrekpunt van die wedergeboorte (Kuyper) nog vanuit die vleeswording (Luther) nog vanuit die versoening (Kohlbrügge) alleen nie. Vanuit die heiliging, soos Calvyn dit uitspel, gaan die perspektiewe werklik oop. Immers, Calvyn stel die gelowige in die orde van God met die opdrag om in alles die eer van God te dien en sy gebooie te gehoorsaam. Hoewel Calvyn se teologie al dikwels, ook in ons tyd, afgewys word as naief of primitief of iets dergliks, is dit ook so dat dit gewoonlik gedoen word om die Bybelse teologie met een of ander vorm van humanisme te vervang.

Wanneer nou oor kerk en kultuur (hoe koddig die teenstelling ook al mag wees) by die $19 \mathrm{e}$ eeuse republikeinse Afrikaner gepraat word, dan sal dit vanuit die gesigshoek van die Calvinistiese teologie moet gebeur omdat dit, in die breë die teologiesgodsdienstige raamwerk is waarbinne die gelowige Afrikanervolk van die vorige eeu geleef, gewerk en bestaan het.

\section{ENKELE OPMERKINGS OOR DIE 19e EEUSE AGTERGRONDE}

Die Afrikanervolk wat gegroei het uit die Nederlandse nedersetting aan die Kaap, was van meet af 'n Christelike volk. In die ruimte van die kerk het die Afrikanervolk tot volk gegroei. Dit het minstens beteken dat die Calvinistiese kerklik-teologiese tradisie in vormende invloed op die wordende Afrikanervolk gehad het. Dit het duidelike gevolge vir die Afrikaner se kultuur en lewenstyl gehad. Dit het beteken dat die Afrikaner van meet af Calvyn se beklemtoning van die soewereiniteit van die lewende, handelende God aanvaar het. Dit het verder meegebring dat die gelowiges dit aanvaar het dat die gelowige se hele bestaanswyse deur gehoorsaamheid aan die Woord en gebod gekenmerk sal word. Geloof volgens die Calvinistiese tradisie voer die gelowige tot die dankbare dien van God as antwoord op die verlossing uit die sonde deur Jesus Christus, die Here. Die lewe en lewenstyl van die gelowige is bepaal deur sy diensbaarheid aan die Drie-enige God. 
Calvyn se visie van die gelowige se lewe in die wêreld word sterk gekleur deur die klem wat hy lê op die selfverloëning en die oordenking van die lewe van die toekomstige eeu (Inst iii 7-10). Calvyn het dit beklemtoon dat die gelowige alle lewensterreine vir die Here sal verower. Daarom is die doei van sy etiek die verheerliking van God en om die kerk in die wêreld heilig te hou. In sy oorweging van die etiek is dit egter steeds duidelik dat die gelowige alleen deur die geloof in Jesus Christus alleen gered word en nie deur die onderhouding van die Wet nie. Die gehoorsaamheid aan die Wet geskied uit dankbaarheid en is nie 'n voorwaarde vir die verlossing nie.

By Calvyn is die besigwees van die mens in die wêreld egter nie 'n saak wat hom baie interesseer nie. Calvyn se opvolgers, die bouers van 'n Protestantse skolastiek en die Calviniste wat beïnloed is deur die Puritanisme (Bronkema 1929:125) en vandaar die voorstanders van die Nadere Reformasie, het meer klem op die vita Cinristiana gelê. Dié aksentverskuiwing het meegebring dat die eis tot goeie werke en die trou aan die respublica Christiana die tipies Calvinistiese eis van 'n reslose vertroue op die beloftes van God, verswak het. Dit het ook na die Afrikaner deurgewerk deur middel van die teologies-stigtelike werke van die Nadere Reformasie en die Puriteinse skrywers wat in die $19 \mathrm{e}$ eeu baie geliefd was. Dit kan gestel word dat, aan die einde van die 18e en die begin van die 19e eeu, hierdie literatuur die geloof en denke van die gelowige Afrikaner sterker beïnloed het as die sporadiese kontak wat hulle byvoorbeeld in die Oosgrens-distrikte met die predikante gehad het (Spoelstra 1963:22-27). Dit beteken dat, op die spoor van Calvyn, die gelowiges hulle lewe en lewensrigting vanuit die heiliging verstaan het, die gelowiges in die heilige orde van God opgeneem is. Dié beklemtoning word uitvoerig deur $\mathrm{W}$ à Brakel uiteengesit en is breed onder die Afrikaner aanvaar (vgl à Brakel 1736:Dl II:315vv). Geloof lei vanselfsprekend tot die dankbare gehoorsaamheid aan die Wet van God wat die heie lewe van die mens moet bepaal en dus vanselfsprekend sy kultuur sal stempel en bepaal (à Brakel 1736:D1 II:30, 'De regel van heyligheyt in de Wet Gods'). Hier volg die etiek op die dogmatiek, maar die belangrike is dat die etiek op die dankbaarheid gegrondves is en nié gesien word as 'n voorwaarde vir die verlossing nie. Dié visie het ' $n$ bepalende invloed op die gelowige Afrikaner se verstaan van die wêreld en sy kultuurtaak daarin gehad. Daarom was in die 19e eeu kerk en volk, Bybel en lewenstyl en lewensinhoud, in die Afrikanergemeenskap onlosmaaklik met mekaar verweef.

As na die wortels van dié lewensopvatting gekyk word, is dit wat die Westerse Christendom betref, 'n tradisie wat geskep is deur Karel die Grote en nie soseer dié wat aan Konstantyn toegedig word nie (Ernst 1982:12). Só 'n verankerdheid in die verbondsteologie was so vanselfsprekend vir die 19e eeuse gelowige Afrikaner dat die rasionalistiese Verligtheid van die $18 \mathrm{e}$ eeu wat die heidense dinkpatrone van die antieke wêreld wou laat herlesf, betreklik min impak op die Afrikaner se geloofs- en kultuurlewe gehad het. 
Dit blyk byvoorbeeld uit die verskynsel van die Patriotdenke onder die Afrikaner aan die einde van die $18 \mathrm{e}$ eeu. Daarin is die opvattings van die Verligtheid oor veral die staatsinrigting en die demokrasie soos dit in Amerika en Frankryk na vore gekom het, via Nederland na Suid-Afrika versprei. Wat na die Kaapkolonie oorgedra is, was die Nederlandse verwerking van die opvattings van die Franse en Engelse Verligtheidsfilosowe (Beyers 1967:200-236). Hoewel die Patriotbeweging 'n stimulus gegee het aan die opkomende nasionalisme van die Afrikaners in die Oosgrens-distrikte is dit opvallend hoe die Patriotdenke getemper is deur die gelowige Afrikaner se godsdienstige opvattings. In sommige gevalle is die Patriotdenke selfs gevul met godsdienstig-bepaalde inhoude. Beyers (1967:281-291) se opmerkings oor die deurwerking van die Patriotıdeale onder die Afrikaner hou nie voldoende rekening met die grondliggende opvattings van die gelowige Afrikaner wat reeds deur Nadere Reformasie-skrywers soos à Brakel bepaal is nie (vgl die manifes van Piet Retief). Die invloed van die Patriotdenke het nagewerk in die denke van die Afrikaner. 'n Mooi voorbeeld is die Patriotspreuk, eendrag maak mag, wat die wapenspreuk van die ou ZAR, die Unie van 1910 en die Republiek van 1961 was. Dit sonder dat die heidense oorsprong van dié spreuk ooit oorweeg is. Daarmee saam kan ook verwys word na die wyse waarop die Afrikaner, noord van die Oranje, sy staat en verteenwoordigende owerheidsliggame gestruktureer het. Hoewel dit miskien formeel gebou was op die republikeinse staatsmodel van die VSA en republikeinse Frankryk, is dit geiemper deur die inhoud wat Kruger, in navolging van rotgieter en Pretorius, aan die begrip volk gegee het.

Naas die invloude van die Patriotdenke is die inhoud en gerigtheid van die Afrikanerkultuur óók gevorm deur die antitese wat ervaar is ten opsigte van die Engelse imperialisme in Suid-Afrika aan die een kant en aan die ander kant die opdringende swart volke wat vanuit Sentraal-Afrika suidwaarts beweeg het. Juis die stryd teen sowel die Engelse imperialisme as die swart volke, dwing die gelowige Afrikaner tot die ontplooiing van sy kultuur en volkseie in eie strukture. Daarvoor is op verskillende maniere weer aansluiting gesoek by Nederlandse strukture, opvattings en gedagtes.

Die merkwaardige van die Afrikanerkultuur van die 19e eeu is dat die gelowige Afrikaner se menswees en volkwees oorwegend bepaal is deur sy geloof in die Drieenige God en die dankbare gehoorsaamheid aan sy gebod soos dit in die Calvinistiese teologie van die $17 \mathrm{e}$ en $18 \mathrm{e}$ eeu verstaan en verwoord is.

\section{KERK EN KULTUUR BY DIE 19e EEUSE AFRIKANER}

Ondanks die probleem wat geskep word deur die teenstelling van die begrippe kerk en kultuur, kan ten opsigte van die Afrikaner in die 19e eeu, tog 'n paar opmerkings oor die twee begrippe gemaak word. 
Die groot, bepalende faktor in die Afrikanervolksbestaan in die 19e eeu was die gebeure van die Groot Trek of, soos dit tydgenootlik bekendgestaan het, de emigratie. Verdruk en onderdruk in die Kaapkolonie wat in 1806 oorgegaan het in die hande van Engeland, was dit veral die beleid van Lord Charles Somerset wat weerstand wakker gemaak het. Vanaf die middel van die dertigerjare begin al meer Afrikaners uit die Oosgrens-distrikte die kolonie verlaat. Daarmee skep die Afrikaner in die $19 \mathrm{e}$ eeu ' $\mathrm{n}$ nuwe volkeregtelike beginsel wat in 1852 met die Sandrivierkonvensie erken is. Dit is dat die Afrikaner hom regmatiglik uit die Engelse kolonie onttrek het en sy burgerskap sodoende prysgegee het. In ieder geval het die Groot Trek die Afrikaner se nasionale identiteitsbesef gestimuleer en sy vryheidsin deel van sy lewensbeskouing gemaak. Merkwaardig genoeg het die Afrikaner se vryheidsin in die 19e eeu meegebring dat hy nêrens 'n swart volk óf onderwerp het aan sy gesag óf gekoloniseer het nie.

In dié uittog en besetting van 'n eie vaderland in die leë binneland van Suidelike Afrika is die Afrikaner se opvattings en beleid in 'n hoë mate bepaal deur sy aanvaarding en uitleef van die verbondsteologie soos dit veral deur à Brakel uitgewerk is (Pont 1991:783-799). Dit het meegebring dat die 19e eeuse Afrikaner se lewensbeskouing metafisies bepaal is en daarom anders was as die 19e eeuse naturalisme soos verwoord in die positiwisme van Auguste Comte en die empirisme van J S Mill wat die natuurwetenskaplike metode op alle verskynsels en probleme wou toepas (Murray 1947:168187).

Dit beklemtoon die breuk in Afrikanervolkseenheid tussen die republikeinse Noorde en die koloniale Suide wat verreikende implikasies gehad het (Bruwer 1988: 151-155). Vanselfsprekend het dit ook 'n belangrike rol in die Afrikaner se kultuurlewe tot gevolg gehad. Dit sou egter te ver voer om dié interessante faset van die Afrikanervolkslewe hier te bespreek.

Die feit dat die republikeinse. Afrikaner se geloof en lewe gedurende die $19 \mathrm{e}$ eeu nogal eensydig bepaal is deur die Calvinistiese Nadere Reformasie sonder verdiskontering van die heidens-bepaalde Verligtheidsdenke, beteken dat die Afrikaner bly vashou en rekening hou met 'n oop wêreldbeeld en die geloof in die lewende Drie-enige God wat nie net die Skepper van alles is nie maar ook die Onderhouer en Regeerder van sy skepping. Dié oppergesag van God wat alles in sy hande het, is nie net die uitgangspunt nie, maar ook die bepalende van die Afrikaner se denke oor homself, sy lewe en sy wêreld.

Dié bewustheid spreek uit die vaste gewoonte van die Afrikaner om elke dorpsaanleg te begin met die uitmeet van 'n sentrale kerkplein, sodat die kerkgebou en alles wat dit impliseer, die sentrum van die gemeenskap sou wees én simboliseer. Dit is verstaanbaar in die geval van 'n volk wat homself gesien het as deel van God se verbonds- 
volk. Daarom is die gelowige huisgesin en die patriargale familie die boustene van sowel die kerk as die volk. Dit kan selfs na vore gebring word dat die gelowige huisgesinne, met die tipies Nadere Reformasie-beklemtoning van die huisgodsdiens, in die $19 \mathrm{e}$ eeu die fondament, menslik gesproke, van kerk én volk was. Waarskynlik kan die gelowige huisgesin, wie se lewensritme gedurende die 19e eeu deur die huisgodsdiens bepaal is, beskou word as die voorbeeld hoe die twee begrippe kerk en kultuur 'n gestalte in die 19e eeuse republikeinse Afrikanervolk gehad het. Hier het die Calvinistiese teologie weliswaar in sy $17 \mathrm{e}$ en $18 \mathrm{e}$ eeuse uitdrukking 'n bepalende rol gespeel.

Op grond daarvan kan gestel word dat die Afrikaner van die $19 \mathrm{e}$ eeu se kultuur jenseitig gerig was en nie eksklusief diesseitig soos die kultuur van imperiale Engeland en die kulture van die swart volkere rondom die Afrikaner nie. Dit dui daarop dat die kultuur van die Afrikaner in die ZAR grotendeels deur sy teologies-godsdienstige opvattings bepaal is, soos byvoorbeeld blyk uit sy vormgewing van die ZAR (Pont 1996:399-408). In die ZAR was die kerk en die burgerlike gemcenskap nie twee aparte gegewenhede nie, maar dieselfde gemeenskap met onderskeie funksies wat ondersteunend ten opsigte van mekaar opgetree het. Vandaar dat die Volksraad en die vereenigde kerkeraad by geleenthede saam vergader het om oor gewigtige staatkundige en kerklike probleme besluite te neem, soos in 1853.

Aan die ander kant is dit ook waar dat die republikeinse Afrikaner nie op alle lewensterreine ' $n$ beslissende rol gespeel het nie. Die ekonomie is byna vanselfsprekend een van dié terreine. Die republikeinse Afrikaner van die $19 \mathrm{e}$ eeu was nog grotendeels 'n pionier wat eers 'n leefwêreld moes bou. Die kultuur van die $19 \mathrm{e}$ eeuse Afrikaner was vir 'n baie groot deel 'n pionierskultuur en in sy samelewing was die Afrikaner dikwels afhanklik van ander soos die Engelse handelaar en die Hollandse immigrant wat die staatsdiens, die spoorweë en die pos- en telegraafdiens moes laat vlot. Tog was dit die Afrikaner wat die geestesklimaat, die gerigtheid en die koers van die gemeenskap bepaal het. Selfs in die mynkamp wat Johannesburg aanvanklik was, het die Afrikaner se Sondagwette en sy landsbeleid die pas aangegee (Nimocks 1968:35).

Dit is en bly opvallend hoe die republikeinse Afrikaner in die $19 \mathrm{e}$ eeu met sy duidelike Calvinistiese teologies-godsdienstige opvattings en die kultuur wat hy vanuit daardie uitgangspunte beleef en gebou het, deur imperialistiese magte wat die bodemrykdomme van die land wou besit, as agterlik, primitief, ensovoorts in sy denke en doen beskrywe is. Dit het 'n eeu later nog nie verander nie. Die republikeinse Afrikaner met sy teokratiese opvattings was in die 19e eeu vir baie 'n struikelblok en 'n ergernis. Tog is dit merkwaardig hoe die Afrikaner vanaf 1852, toe die onafhanklikheid van die Oorvaalse erken is, in ongeveer 48 jaar daarin geslaag het om 'n land- en volksgemeenskap te bou op die basiese patroon van die Calvinistiese teologie (Du Plessis 1952:55-74). 


\section{ENKELE SAMEVATTENDE OPMERKINGS}

Die eerste gevolgtrekking wat uit hierdie kort oorsig gemaak kan word, is dat die gelowige Afrikaner van die 19e eeu, die doelwit van sy lewe anderkant hierdie lew. gestel het. Sy gerigtheid op die beloftes van die lewende God en veral op die wederkoms van Christus, het sy kultuur en lewenstyl wat van hierdie wêreld is, gekersten. So is in die $19 \mathrm{e}$ eeu die grondslae gelê van wat later bekend geword het as die Afrikaner se Christelik-nasionale mensopratting en lewensbeskouing (Muller 1913:27). In hierdie verband is dit opvallend hoe die Afrikaner in die noordelike republieke ook in sy kultuurlewe steeds gepoog het om vas te hou aan die vaste uitgangspunte en gerigtheid van die Bybelse teologie soos hy dit vanuit die Calvinisme verstaan het.

Die tweede gevolgtrekking is dat die verbondsteologie van à Brakel, wat so 'n breë aanvaarding gehad het, 'n groot rol gespeel het in die Afrikaner se siening van homself. As deel van God se verbondsvolk het die Afrikaner 'n parallel gesien tussen sy soeke na en opbou van 'n eie vaderland en die geskiedenis van die volk Israel. Daarom het hulle alles van die lewende God verwag. Opvallend van die 19e eeuse republikeinse Afrikaner was sy konsekwente praktyk om nie met die swart volkere te vermeng nie, hulle nie te onderwerp en te koloniseer nie of in die Afrikaner se staatkundige strukture op te neem nie. Hulle is as səlfstandige volke langs die Afrikaner beskou en aanvaar. Of dié opvattings bepaal is deur die teologie (Hellenbroek $s$ a:80), deur 'n lewenswysheid wat uit die Engels-koloniale wêreld gekom het (Haasbroek $s$ a:47-52), en of dit bepaal is deur die ervaring van die werklikhede van Afrika, kan vandag nie meer trefseker uitgemaak word nie. Dit is egter een van die erfenisse uit die vorige eeu wat 'n merkwaardige duursaamheid het (Francis 1995:6-7).

'n Verdere merkwaardigheid van die 19e eeuse Afrikanerkultuur was dat dit nooit toegelaat is om selfstandig te ontwikkel nie. Hoewel die republikeinse Afrikaner van 1852-1877 in die ZAR soewerein onafhanklik was en van 1881-1902 sekere beperkings moes aanvaar, is die Afrikaner vanaf 1853 veral op kulturele en kerklike gebied voortdurend onder druk geplaas. Dit het op hierdie terrein daaroor gegaan of die republikeinse Afrikaner kultureel-godsdienstig aansluiting sou soek by die Afrikaanssprekendes in die Engelse Kaapkolonie en of hy steun sou soek in Nederland. In daardie strydom-'n-beleid het die Hervormde Kerk 'n paar stewige knoue gekry omdat dit op hierdie vlak die Potgieter-Pretorius-Kruger-beleid gesteun het. Teologies-godsdienstig-kultureel het die aansluiting by Nederland tog groot winste vir die Afrikaner opgelewer. Hier is dit egter opvallend dat teologies-verskillende uitgangspunte tog verskillende, selfs botsende, kerklike kulture skep wat saamgaan in én struktuur bemoeilik, soos die kerkverenigingspoging van 1885 aangetoon het.

Wanneer so gelet word op kerk én kultuur by die vryheidsoekende Afrikaner van die 19e eeu, is dit duidelik dat sowel die kerk as die kultuur van die volk wat deur die geloof van die kerk bepaal en gevorm is, duidelike grense getrek het, sodat die Afrika- 
ner 'n eiesoortige identiteit ontwikkel het. Die kerk het as 't ware begin deur grense te trek. 'n Eerste grens was dié tussen geloof en ongeloof, gelowige en nie-gelowige. Maar die kerk het ook teologiese grense getrek, tussen kerk en kerk. Net so het die kultuur $66 \mathrm{k}$ grense getrek tussen eie en nie-eie. Opmerklik in hierdie verband is dat selfs in die 19e eeu die volk vir die Afrikaner belangriker was as die enkeling, die geheel méér was as die dele. Daarom is daar soveel moeite gedoen om die partyskappe te oorwin en om die grondwet van die ZAR so te struktureer dat daar nie ruimte was vir politieke partye nie.

Dit is opvallend in die 19e eeu dat die kerk, behalwe op sy eie terrein waar die poging misluk het, nooit probeer het om bestaande en natuurlike grense te oorbrug of uit te wis nie. Dié strewe, deur middel van social engineering, is iets van hierdie eeu. As die vraag na kerk en kultuur in die vurige eeu gevra word met die doel om vas te stel of die kerk tóé gebruik is om nie-kerklike doelwitte in die volk of gemeenskap na te jaag, is die antwoord negatief. Wat wel gebeur het, is dat die boodskap van die kerk die kultuur nie alleen deursuur het nie maar ook gekersten en bepaal het. Die sekularisasie van die kerk wat in die $19 \mathrm{e}$ eeu in Europa begin is met die invoer van die Verligtheidsteologie het gedurende die 19e eeu onder die republikeinse Afrikaner geen noemenswaardige invloed gehad nie. Daarmee is, in sekere sin ook die vraag beantwoord of die kultuur die kerk beïnvloed het. Dié vraag is, soos reeds genoem, byna onbeantwoordbaar want die geloofsgemeenskap wat die kerk is, was vir alle praktiese redes óók die kultuurgemeenskap. So gesien was die volkskerklike denke, wat uit die verbondsteologie voortgekom het, ook vanselfsprekend veral as in ag geneem word dat die kerk bestaan het uit gelowige huisgesinne en families. Dit is eers in ons eeu waar daar geleidelik, met die doelbewuste sekularisasie van die volksgemeenskap, 'n afstand ontwikkel het, ook in die Afrikanervolk, tussen strominge in die kultuurgemeenskap en die geloofsgemeenskap. Die afstand word vanuit die kerk ook bewustelik beklemtoon deur die popularisering van die $19 \mathrm{e}$ eeuse dwaasheid dat daar 'n antitese moet wees tussen die geloofsgemeenskap en die politisk en ook die ekonomie en derglike. Dan word die godsdiens, gerieflikheidshalwe, aangedui as so iets soos 'n private aangeleentheid en die geloofsgemeenskap teruggedruk uit die hoofstroom van die volkslewe. Alleen met die verloëning van sy Calvinistiese erfenis kan die geloofsgemeenskap dié on-Bybelse opvatting aanvaar. As die saak egter verder beredeneer moet word, gaan dit nie meer oor die $19 \mathrm{e}$ eeuse republikeinse Afrikaner van die Noorde nie.

\section{Literatuurverwysings}

à Brakel, W 1736. Redelyke godtsdienst. Rotterdam: Wed H van den Aak.

Beyers, C 1967. Die Kaapse Patriotte. Pretoria: J L van Schaik. 
Bronkema, R 1929. The essence of Puritanism. Goes: Oosterbaan en Le Cointre. Bruwer, P F 1988. Vir volk en vryheid. Morgenzon: Oranjewerkers Promosies.

Calvinus, J 1559. Institutio christianae religionis, in Baum, G, Cunitz E, Reuss E (eds) 1863-1900, loannis Calvinus opera quae supersunt omnia. Brunsvigae: G A Schwetscke et filium.

Du Plessis, J S 1952. President Kruger aan die woord. Bloemfontein: Sacum.

Emst, S s a. Thine is the kingdom. Ulm: Europäische Aertze-Aktion e V.

Francis, S 1995. Prospects for racial and cultural survical, in American Renaissance 6/3, 4-12.

Haasbroek, D J P s a. The interpretation of race attitudes by South African historians. Humanitas RSA 2/1, 47-52.

Hellenbroek, A 1706. Voorbeeld der goddelyke waarheden. Herdruk 1984. Utrecht: De Banier.

Kinnanom, M 1991. Signs of the Spirit. Official report 7th Assembly (Canberra 1991). Geneva: W C C Publications.

Labuschagne, J P 1907. Die historiese konteks van 20ste eeuse samelewingsteologieè. DD-proefskrif, Universiteit van Pretoria.

Muller, T 1913. Die geloofsbelydenis van 'n nasionalist. Herdruk 1972. Pretoria: CKA.

Murray, A H 1947. Die Afrikaner se wysgerige denke, in Van den Heever, C M \& Pienaar, P de V (reds), Kultuurgeskiedenis van die Afrikaner, Deel II, 164-187. Kaapstad: Nasionale Pers.

Nimocks, W 1970. Milner's young men. London: Hodder and Stoughton.

Pont, A D 1991. Die verhouding kerk en volk in die jare 1835-1900 in die Oorvaalse. 'n Terreinverkenning. HTS 47, 783-799.

1996. Enkele opmerkings by die vormgewing van die eerste grondwet en kerkwet in die ZAR in die jare 1857-1858. NGTT 36, 399-408.

Spoelstra, B 1963. Die 'Doppers' in Suid-Afrika 1760-1899. Kaapstad: Nasionale Boekhandel.

Taylor, J 1992. Paved with good intentions: The failure of race relations in contemporary America. New York: Carroll \& Graf.

Van Niekerk, A 1992. Sáám in Afrika. Kaapstad: Tafelberg Uitgewers Bpk.

Van Ruler, A A 1938. Natuur en genade. Onder Eigen Vaandel 13, 188-202.

s a. Kuypers idee eener Christelijke cultuur. Nijkerk: G F Callenbach. 